\title{
Exploring the Impact of LMX Fit Type on Employee's Behavior Perception
}

\author{
Li Huang \\ Yunnan University of Finance and Economics \\ Kunming, Yunnan, China \\ e-mail: huangli0416@126.com \\ Shiqing Ding \\ Yunnan University of Finance and Economics \\ Kunming, Yunnan, China \\ e-mail: sding203@163.com
}

\author{
Yunnan University of Finance and Economics \\ Kunming, Yunnan, China \\ e-mail:Chna@ynufe.edu.cn \\ *Corresponding Author \\ Dongshu Jiang \\ Yunnan University of Finance and Economics \\ Kunming, Yunnan, China \\ e-mail: Roryjds@163.com
}

\begin{abstract}
In the research of organizational behaviors, there are two typical leader-member exchanges (LMX). Some are high quality exchange based on high trust and obligation. Others are low quality exchange relationships based on economic and interest. Recently, the domestic and foreign scholars proposed four types of LMX fit, including double high, follower overestimation, leader overestimation, and double low. This study explored the effect of LMX fit on employees' supportive and abusive behaviors perceptions. The results of statistical analysis from 380 dyads of questionnaires of subordinates and their immediate supervisors shows: (1) The forms of double high and follower overestimation have a positive impact on employee's supportive behavior; while the forms of perceptions fit of leader overestimation and double low have a negative impact on employee's supportive behavior. (2) The forms of double high and follower overestimation have a positively inhibitory factor on employee's abusive behavior; while the forms of double low and leader overestimation are as the evoked situational factors of employee's abusive behavior perception.
\end{abstract}

Keywords- leader-member exchange; leader- member exchange type; supportive behavior; abusive behavior; dual perspective

\section{INTRODUCATION}

Managers as is a complex individual, his behavior has two sides or even multi-faceted. The manager may exhibit positively supportive or negatively abusive behavior to the same subordinate in different situations. A theory worth pondering the question is that what is situational factor causes differences in perception of behaviors of managers?

The different relationship between leaders and subordinates may be an important situational factor influencing managers' behavior perception. Leaders and subordinates based on different positions may form different leader-member exchange (LMX). The studies have shown that the correlation between perception of leaders' LMX and subordinates' LMX is significantly weak. The different perspectives of LMX perception is not consistent (Gerstner \& Day, 1997) ${ }^{[1]}$. So some studies adopted perceive LMX fit type to explore ${ }^{[2][3]}$. The study focused on the core problem is the effect of perceived LMX type on managers' behavior based dual perspective. This study can improve the perception of managers' positive behavior and enhance LMX.

\section{LITERATURE AND HYPOTHSIS}

\section{A $I M X$ and LMX fit type}

LMX theory suggests that managers treat subordinates unequally, and form the different social exchange. Managers and insiders will establish a high-quality LMX based on mutual obligation and trust. Managers will maintain low-quality LMX with outsiders based on jobs and contracts. The perception LMX from dual perspective will form four types ${ }^{[4]}$ :

The study is fund by the National Nature Science foundation of China(71462031), Ministry of Education and Science Planning Projects Social Science(12YJA630092), Planning Project in Yunnan (QN2014081), Educational Fund for Scientific Research Project in Yunnan(2014Y286; 2014Y287), Yunnan University of Finance and Economics(YC2014D09) 


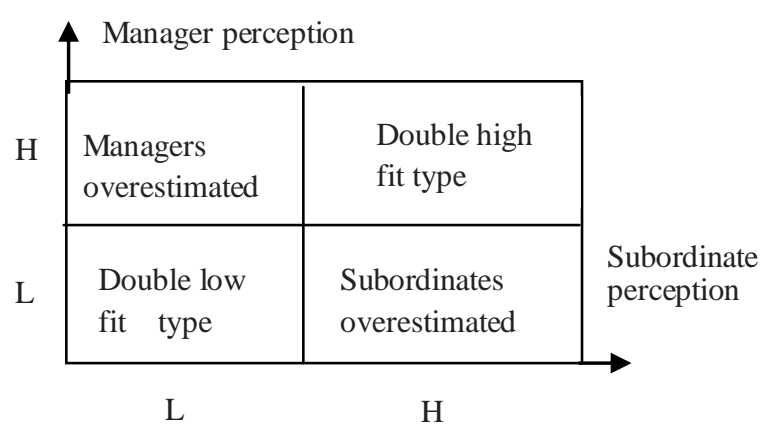

Figure 1. LMX fit type from two dimensions

Figure 1 shows that the perception LMX of subordinates is consistent with managers in a double high and low types, while in the other two types, there are obvious differences in perception of LMX. A detailed analysis of four types is followed:

Double high fit type: a mutual cooperation and win-win relationship. Supervisor would provide more autonomy and support for subordinates. Subordinates clearly perceive the care and trust, and take a greater the obligation to return trust and respect.

Managers overestimated type: Managers have a greater quality exchange perception level, while subordinates have a lower level. Supervisors actively provide additional trust and help for subordinates, but the subordinate does not seem to recognize, possibly negatively understand, and even distort the information conveyed by the manager.

Double low fit type: A low-quality of transactional or economical social exchange relationships lack of In-depth interaction and understanding between managers and subordinates. Managers do not take the initiative to care and support subordinates outside of work. So, it is difficult to expect subordinates undertake the responsibility and obligation.

Subordinates overestimated type: Subordinates have confidence in establishing mutual respect and recognition relationship, and pay efforts and behaviors beyond the requirements of the role. Managers do not pay the extra help and support, and viewed as a purely economic contractual relationship.

$B$ supportive leadership and abusive supervision

Supportive and abusive acts are the typically positive or negative behaviors of the manager. Supportive leadership refer that managers friendly treat and respect of subordinates, also care emotions and needs of subordinates(Rafferty \& Griffin, 2006 ${ }^{[5]}$.The specific supportive leadership behaviors are: sincere concern subordinates'life; recognize the contribution for enterprise; provide guidance and assistance to subordinates' work; trust; support career development and safeguard their interests; frank communication with subordinates, and provide information, fair, just and reasonable evaluation; encourage autonomous decision-making.

Abusive supervision refers to managers continued to show a hostile verbal and nonverbal behavior to subordinate, but does not include physical contact. Tepper et al(2004) speculated that 10\%-16\% employees suffered varying degrees of abusive management in $\mathrm{USA}^{[6]}$. Abusive supervision in Western literature specifically refers ridicule, public criticism, angry, rude, indifferent, and contemptuous language to subordinates.

\section{Research Hypothesis}

1) The impact of LMX fit type on supportive leadership. In high-quality and harmonious of double high fit LMX type, the mutual trust peer exchange beyond the boundaries of work between managers and subordinates is established. Managers and subordinates both feel the opponent's pay and sincerity, and form a good mutually beneficial feedback loop(Zhou Nina, 2010) [3]. Therefore, subordinates tend to active attribution of manager behaviors and more feel the supportive acts. Manager might tend to think that subordinates are not reliable, and consciously or unconsciously reduce the support and assistance given to subordinates. Therefore, subordinates maintain the lower perception of support behavior of managers. Subordinates unilaterally identified themselves as insiders of the managers, and were favored by managers, were given more help, trust and resources in subordinates 'overestimated LMX type. Before the cognitive adjustment, subordinates still keep positive expectations to managers, and feel relatively more support behavior of managers. In managers 'overestimated LMX type, although managers claim to give subordinates more support and care, employees do not recognize and approve it. Subordinates may think that the managers are selfish, treat themselves 
as insiders. Therefore, the perception of managers' support conduct is not profound. The following hypotheses have been proposed:

Hypothesis 1: LMX fit type has a significant effect on the perception of supportive leadership. The different LMX fit types have distinguished impact on the perception of supportive leadership.

H1a: Subordinates perceived the highest level of support leadership in double-high type;

H1b: Subordinates perceived the higher level of support leadership in subordinate overestimated;

H1c: Subordinates perceived the lower level of support leadership in manager overestimated;

H1d: Subordinates perceived the lowest level of support leadership in double-low type.

2) The impact of LMX fit type on abusive behaviors of managers. The perception of managers' abusive behaviors not only affected by stable factors, such as self-esteem, but also influenced by situational factors including LMX and so on ${ }^{[7]}$. Double high fit type is a stable, sustained positive and mutually beneficial relationship. The psychological distance is small, and both sides pay a lot of effort and effort to maintain. Managers will greatly constrain the abusive behavior with a negative effect to subordinates. Therefore, subordinates rarely perceive abusive behaviors of managers. Conversely in the double- low fit type, Leaders focus on the work effectiveness of subordinates, and may often apply "authoritarian", "patriarchal" behaviors to facilitate the satisfactory work performance. The bureaucratic styles, such as authoritarian, arbitrary, forced, rough and so on are mainly attributed to abusive management by subordinates. In subordinates' overestimated type, employees tend to tolerance and positive attribution of abusive supervision. The internal reasoning and cognitive processes of subordinates will reduce the perception of abusive supervision. In managers' overestimated type, although managers think of rare implementation of abusive behavior to subordinates, subordinates may overestimate the frequency of abusive behavior occurrence, resulting in improper information communication of managers, or prejudice and misunderstanding information of subordinates. The following hypotheses have been proposed:
Hypothesis 2: LMX fit type has a significant effect on the perception of abusive supervision. The different LMX fit types have distinguished impact on the perception of abusive supervision.

H2a: Subordinates perceived the lowest level of abusive supervision in double-high type;

$\mathrm{H} 2 \mathrm{~b}$ : Subordinates perceived the lower level of abusive supervision in subordinate overestimated;

$\mathrm{H} 2 \mathrm{c}$ : Subordinates perceived the higher level of abusive supervision in manager overestimated;

$\mathrm{H} 2 \mathrm{~d}$ : Subordinates perceived the highest level of abusive supervision in double-low type.

According to LMX evaluation from dual perspective, and above theoretical analysis and research hypothesis, the relationship of variables is appeared in Figure 2:

\begin{tabular}{|c|c|c|}
\hline \multicolumn{2}{|c|}{ LMX fit type } & \multirow[t]{2}{*}{ Managers behavior } \\
\hline Managers & & \\
\hline Overestimate & Double high & Supportive behavior \\
\hline Double low & $\begin{array}{l}\text { Subordinates } \\
\text { overestimate }\end{array}$ & Abusive behavior \\
\hline
\end{tabular}

Figure 2 study variables diagram

\section{RESEARCH METHODS}

\section{A Subjects and procedure}

We adopt pair questionnaire research to avoid the common method variance. Three ways are used to collect questionnaires including MBA, HRM training, corporate survey and commissioned survey. A paired coding questionnaire is commissioned to subject, asking them to complete employer questionnaire. Manager send employee questionnaire to appropriate subordinate. Manager and subordinate respectively seal stamped to the investigation team. According to the code, we excluded unsuccessful paired questionnaire.

\section{B Sample Overview}

Total 768 sets of paired questionnaires are delivered and recovered 412 sets. We exclude 32 sets ineffective questionnaires and finally collect 380 sets of valid questionnaires. The proportion of valid questionnaire is $49.48 \%$. In 380 sets of valid questionnaires, 225 sets from MBA and HRM training, 112 sets from businesses field, 43 sets from the commission, the respective rate of total effective matching sample survey is $59.21 \%, 29.47 \%$ and 
$11.32 \%$

Demographic variables including gender, age, education and position respectively were reported by the immediate supervisor and their employees. In manager sample, the company nature and the industry categories were reported by the immediate supervisor. The proportion of male was $64.47 \%$, the average age and work experience respectively were 36.38 and 9.48. The education level of college $(30.53 \%)$ and bachelor $(45.79 \%)$ is primary (high or secondary school $13.42 \%$, master degree or above $10.26 \%$ ); the position level of level managers $(31.32 \%)$ and middle managers $(56.58 \%)$ were primary(senior managers $12.10 \%$ ). In subordinate sample, the proportion of male was55.3\%, the average age and work experience respectively were 30.89 and 5.98. The education level of college (35.26\%) and bachelor (37.63\%) was primary (high or secondary school $23.16 \%$, Master degree or above $3.95 \%$ ); the position level of general staff (54.21\%) was primary(level managers $29.21 \%$; middle managers $14.47 \%$ and senior managers $2.11 \%)$.The distribution of the nature company mainly was private company $(44.47 \%)$ (state-owned holding companies $39.21 \%$, foreign-controlled companies $16.32 \%$ ); the distribution of industry categories primarily was service sector(33.25\%)(Percent of IT/ communications/high-tech industry was 31.58, traditional manufacturing/construction/real estate was $19.04 \%$ and other $16.13 \%$ ).

C. research tools and measurement

Leadership-Member exchange (LMX). Employee' evaluation directly adopts Graen \& Uhlbien development of the one-dimensional Scale ${ }^{[8]}$. The scale includes 7 items, such as "immediate supervisor fully understand my problems and personal needs at work". Employer' evaluation slightly adjusts the expression, including items "I fully understand his/her problems and personal needs at work".

LMX fit type. According the classification method of Cogliser et $\mathrm{al}^{[4]}$, the samples of managers' and subordinates' LMX are divided into half with the demarcation of average score. The scorns LMX of both paired samples are greater than the mean and as be "Double high type". The scorns LMX of both paired samples are less than the mean and as be "Double low type". The scorn of manager' LMX evaluation is greater than the mean, and the subordinate evaluation score less than the mean which called "managers overestimated type". The scorn of manager' LMX evaluation is less than or equal the mean, and the subordinate evaluation score greater than the mean which is called "subordinate overestimated type". So, it forms four types of LMX fit: Double-high type $(110,28.9 \%)$, double-low type(111, $29.2 \%)$, managers overestimated $(83,21.8 \%)$ and subordinates overestimated type $(76,20 \%)$.

The perception of supportive behavior of managers: Oldham \& Cummings (1996) developing a single dimension scales are adopted, including 8 items such as "My immediate supervisor helps me solve work-related problems". It is reported by subordinates according to the actual situation $^{[9]}$.

The perception of abusive behavior of managers: Mitchell \& Ambrose (2007) developing the short single-dimension development scale, including "My boss used to say directly subordinate thoughts and feelings are stupid" and so on. It is reported by subordinates according to the actual sitution ${ }^{[10]}$.

\section{THE RESULT OF STUDY}

\section{A Reliability and validity study variables}

Cronbach's $\alpha$ coefficient is used to measure consistency reliability of the scales(see Table 2) and confirmatory factor analysis is used to test construct validity, see Table 1.

TABLE 1 reliability and validity test $(\mathrm{N}=380)$

\begin{tabular}{|l|c|c|c|c|c|c|c|c|}
\hline \multicolumn{1}{|c|}{ index } & $\chi^{2} / \boldsymbol{d f}$ & RMSEA & AGFI & GFI & IFI & CFI & NFI & NNFI \\
\hline scale & & & & & & & & \\
\hline LMX - Subordinate & 2.273 & .058 & .951 & .977 & .984 & .984 & .972 & .974 \\
\hline Supportive behavior & 2.205 & .076 & .936 & .982 & .978 & .978 & .969 & .943 \\
\hline Abusive behavior & 1.539 & 0.038 & 0.977 & 0.995 & 0.999 & 0.999 & 0.997 & 0.997 \\
\hline
\end{tabular}

The results showed that Cronbach's $\alpha$ values are above or close to the 0.80 criterion, indicating good 
internal consistency reliability of scales. The results of confirmatory factor analysis that $\chi^{2} / \mathrm{df}$ values are less than 5, RMSEA values are less than 0.08 , the rest of the index values are above 0.90 criterion, indicating the selected scale showed good construct validity ${ }^{[11]}$.

\section{$B$ the related analysis of variables}

The mean, standard deviation and correlation coefficient of variables are shown in Table 2.

TABLE 2 M、SD and correlation coefficient

\begin{tabular}{|l|c|c|c|c|c|c|}
\hline Variables & $\mathbf{M}$ & SD & $\mathbf{1}$ & $\mathbf{2}$ & $\mathbf{3}$ & \\
\hline 1. LMX-Subordinates & 3.544 & .693 & $(.839)$ & & & \\
\hline 2. LMX-Managers & 3.606 & .614 & $.173 * *$ & $(.798)$ & & \\
\hline 3. supportive behavior & 3.766 & .806 & $.601 * *$ & $.214 * *$ & $(.878)$ & \\
\hline 4.abusive behavior & 1.369 & .713 & $-.314 * *$ & $-.126 *$ & $-.453 * *$ & $(.934)$ \\
\hline
\end{tabular}

(Note:*p<0.05, ** p<0.01; Cronbach's $\alpha$ in oblique bracket)

The results showed that the low correlation coefficient between the perception LMX of subordinates and managers. The perception LMX of subordinates and managers has significant correlation with supportive and abusive behaviors, supporting the hypothesis of this study.

TABLE 3 the effect of LMX fit on perception of manager "behavior $(\mathrm{N}=380)$

\begin{tabular}{|l|l|l|l|l|l|l|l|l|}
\hline \multirow{2}{*}{$\begin{array}{l}\text { Manager, } \\
\text { behavior }\end{array}$} & \multicolumn{4}{|c|}{ LMX fit type } & \multicolumn{2}{c|}{ ANOVA } & \multicolumn{2}{l|}{ MANOVA } \\
\cline { 2 - 10 } & $\begin{array}{l}\text { Double } \\
\text { high }\end{array}$ & $\begin{array}{l}\text { Subordinates } \\
\text { overestimate }\end{array}$ & $\begin{array}{l}\text { Double } \\
\text { low }\end{array}$ & $\begin{array}{l}\text { Managers } \\
\text { overestimate }\end{array}$ & $\begin{array}{l}\text { F } \\
\text { value }\end{array}$ & $\begin{array}{l}\text { P } \\
\text { value }\end{array}$ & Falue & value \\
\hline Supportive M & 4.217 & 4.028 & 3.292 & 3.563 & $36.797 * *$ & .000 & $34.431 * *$ & .000 \\
\hline Abusive M & 1.104 & 1.190 & 1.628 & 1.537 & $14.494 * *$ & .000 & $13.987 * *$ & .000 \\
\hline
\end{tabular}

The above table shows that there are significant difference in a variety of LMX fit type on perceived managers' supportive and abusive behavior.LSD

TABLE 4. the result of LSD of perceived leadership behavior

\begin{tabular}{|c|c|c|c|c|}
\hline $\begin{array}{l}\text { Dependent } \\
\text { variable }\end{array}$ & (I) LMX fit type & (J) LMX fit type & Mean(I-J) & Sig \\
\hline \multirow{6}{*}{$\begin{array}{l}\text { Supportive } \\
\text { leadership }\end{array}$} & Double high & Subordinates overestimated & .189 & .076 \\
\hline & Double high & Double low & $.925^{* *}$ & .000 \\
\hline & Double high & Managers overestimated & $.654 * *$ & .000 \\
\hline & Subordinates overestimated & Double low & $.736 * *$ & .000 \\
\hline & Subordinates overestimated & Managers overestimated & $.465 * *$ & .000 \\
\hline & Double low & Managers overestimated & $-.271 * *$ & .009 \\
\hline \multirow{6}{*}{$\begin{array}{l}\text { Abusive } \\
\text { supervision }\end{array}$} & Double high & Subordinates overestimated & -.086 & .396 \\
\hline & Double high & Double low & $-.524 * *$ & .000 \\
\hline & Double high & Managers overestimated & $-.433 * *$ & .000 \\
\hline & Subordinates overestimated & Double low & $-.438 * *$ & .000 \\
\hline & Subordinates overestimated & Managers overestimated & $-.347 * *$ & .001 \\
\hline & Double low & Managers overestimated & .091 & .355 \\
\hline
\end{tabular}


Above table shows that there is no significant difference between the double high fit and subordinates overestimated type, but there are significant differences in else types on perceived supportive behavior. There was no significant difference between the double high fit and subordinates, between double low fit and managers overestimated type, but there are significant differences in else types on perceived abusive behavior.

\section{DISCUSSION AND PROSPECTS}

\section{A result discussions}

Empirical studies have found a low correlation coefficient between the perception LMX of subordinates and managers, which show the greater difference the perception of Leader-member exchange quality from perspective of subordinates and managers. There are certain limitations evaluating LMX from subordinates' perception. LMX is as an index reflecting the two-way interactive activities. Two-way perspective of subordinates and managers should be taking into account in the study. These factors including different personality, upbringing, work experience and even cognitive style of leaders and subordinates et al have caused the differences perception of LMX quality that lead to different consequences.

The result of descriptive statistics indicate that average score of the perception of managers' support behavior is $\mathrm{M}=3.766$, higher than the median (Median=3). This shows that in management practices, managers mainly adopted a positive, active support behavior to subordinates. The average score of the perception of managers' abusive behavior is $M=1.369$, far below the median (Median=3). One hand, it reflects that the majority of managers is self-discipline, can restrain their abusive behavior which may result from physical or mental harm to subordinate hurt. The other hand, it shows the existence of abuses. The behaviors of managers can be improved. An adequate attention should be given to abusive behavior and must not drift it. Enterprise should plan ahead, make advance intervene to prevent abusive behavior of manager.

The results of ANOVA and MULITIVARIATE analysis show that LMX types have a significant impact on the perception of managers' behaviors. The descending order of the perception of managers' supportive behaviors by employees is: double high fit type $(M=4.217)>$ subordinates overestimated type $(\mathrm{M}=4.028)>$ managers overestimated type $(\mathrm{M}=3.563)>$ double low fit type $(\mathrm{M}=3.292)$. In double-high fit type and subordinates overestimated type, the degree of perceived supportive behaviors of managers by subordinates is higher than the average scorn of supportive behaviors( $M=3.766)$. In the other types, the degree of perceived supportive behaviors of managers by subordinates is less than average scorn. Double-high fit type and subordinates overestimated type have a positive impact on supportive behaviors, while managers overestimated type and double low fit type has a negative impact. The descending order of the perception of managers' abusive behaviors by employees is: double low fit type $(M=1.628)>$ managers overestimated type $(\mathrm{M}=1.537)>$ subordinates overestimated type $(\mathrm{M}=1.190)>$ double high type( $\mathrm{M}=1.104)$. In double-high type and subordinates overestimated type, the degree of perceived abusive behaviors of managers by subordinates is less than the average scorn of supportive behaviors(M=1.369). In the other types, the degree of perceived supportive behaviors of managers by subordinates is higher than average scorn. Double-high fit type and subordinates overestimated type have a positive inhibition impact on abusive behaviors, while managers overestimated type and double low fit type.

\section{B. Management implication}

This study confirms that LMX fit type has a significant impact perceived managers' behavior. Thus, LMX fit type should be discriminated in practice to reduce the perception of abusive behavior and enhance the perception of supportive behavior of managers:

1) Double high fit type: Managers should choose a positive, sunny supportive behavior, and abandon hostile words and actions to attack subordinates. Managers should proactive care the growth of subordinates, provide support and assistance, and full affirm the contribution and value of subsidiaries. Also, subordinates should pay more efforts to improve work performance, make managers fully awarding of own' value and contribution.

2) Managers overestimated type: Affected Chinese Confucian cultural, managers inherit "patriarch" 
enforcement management. Therefore, leadership behavior of "authoritarian" and "patriarchal" has been widely popular. Their behavior has feature with totalitarian, arbitrary and forced, rough. Subordinates may not appreciate this stressed absolute obedience. Managers should adopt contingency management approach to subordinates, and understand the internal needs, provide understanding and support in accordance with subordinate' needs. In addition, managers should timely eliminate mutual misunderstanding.

3) Subordinates overestimated type: Subordinates may maintain positive attribution tendency, and even exaggerate supportive behavior of managers in the short term, but if managers don't adjust and improve negative behavior, initiative increase attention and understanding, subordinates will feel indifferent of manager in continuous social comparison, and then breed resentment and anger. Subordinates overestimated LMX type is likely to develop into double low type. At this point, the remedial measures may have been too late.

In summary, double high fit LMX should be established in practices. A two-way identity of subordinates and managers is more valuable. Mangers should adjust and repair timely double low fit LMX to overcome vicious circle.

\section{Limitations and prospect}

This study has the following deficiencies: (1) The data is collected mainly from companies in the western regions. Its representation may be slightly less. In addition, hierarchical linear modeling method should be a better choice in process of data analysis. In the future, the different geographical samples should be expanded to improve the reliability and applicability of findings. (2) In this study, although the pair questionnaire can overcome CMV, some sensitive questions with social desirability may affect findings, so the questions examining social desirability should be added

\section{References}

[1] Gerstner, C. R. \& Day, D.V. Meta-Analytic Review of Leader-Member Exchange Theory: Correlates and Construct issues[J]. Journal of Applied Psychology, 1997, 82(6):827-844.
[2] Chen Tongyang, Tan Liang, Cao Guonian. A Study on Formation Mechanism of Perceptions of Leader-member Exchange Fit: Based on the View of Organizational Support[J]. Nankai Business Review, 2013, 16(3): 118-126.

[3] Zhou Nina. Balance in Leader and Follower Perception of Leader-Member Exchange: Relationship with Employee’ Attitudes and Behaviors[J]. Research on Economic and Management, 2010, 7: $67-76$.

[4] Cogliser, C. C., Schriesheim, C. A., Scandura, T. A., \& Gardner. W. L. Balance in Leader and Follower Perceptions of Leader-Member Exchange: Relationships with Performance and Work Attitudes[J]. The Leadership Quarterly, 2009, 20(3): 452-465.

[5] Rafferty A.E. Griffin M. A. Refining Individualized Consideration: Distinguishing Development Leadership and Supportive Leadership $[\mathrm{J}]$. Journal of Occupational and Organizational Psychology, 2006, 27(1):37-61.

[6] Tepper, B. J., Duffy, M. K., Hoobler, J. M.,Ensley, M. D Moderators of the Relationships between Coworkers Organizational Citizenship Behavior and Fellow Employees' Attitudes[J]. Journal of Applied Psychology, 2004, 89(3): 455-465.

[7] Martinko, M.J., Sikora, D. \& Harvey, P. The Relationships between Attribution Styles, LMX, and Perceptions of Abusive Supervision[J]. Journal of Leadership \& Organizational Studies, 2012, 19(4): 397-406.

[8] Graen, G. B. \& Uhl-Bien, M. Development of Leader-member Exchange (LMX) Thoery of Leadership over 25 Years: Applying a Multi-level Multi-domain Perspective[J]. Leadership Quarterly, 1995, 6(2): 219-247.

[9] Oldham, G. R. \& Cummings, A. Employee creativity: Personal and Contextual Factors at Work[J]. Academy of management journal, 1996, 39(3):607-634.

[10] Mitchell, M. S., \& Ambrose, M. L. Abusive Supervision and Workplace Deviance and the Moderating Effects of Negative Reciprocity Beliefs[J]. Journal of Applied Psychology, 2007, 92(4): 1159-1168.

[11] Wu Minglong. Questionnaire Statistical Analysis Practice: SPSS operation and Application[M] Chongqing University Press, 2010. 